lettre to you, I suffre such to weary out themselves. I think him worthy of contempt not of opposition wch would make the world thinke there were something good in him $\mathrm{y}^{\mathrm{t}}$ might disadvantage me. Let him therefore not think of me, as I doe not of him, being neither sorry for his stay, nor glad for removall. This in haste $w^{\text {th }}$ my fond love.to you I rest,

$$
\text { yor very loving friend }
$$

John Symcottes.

Remember my service to Mrs Willis.

Dec: 20: 1636.

Bathe yor eyelidd, wth the water in the glasse oftentymes in the day, at $\mathrm{y}^{\mathrm{r}}$ pleasure and now and then you may dropp a dropp or 2 into $\mathrm{y}^{\mathrm{r}}$ eye especially to bedward and every night to bedward swallow doune 2 of the pills in the boxe, and soe rest.

And every morning fasting, and also about halfe an houre after meales, eate soe much of the powder in the paper as you can take up $w^{\text {th }}$ a shillinge.

Alsoe use yor we ointment yet somtymes, as before."

The writer of this letter was admitted, as John Symcotes, pensioner, at Queens' College, Cambridge, April, 1608. He was the son of John Simcotes, of Sutton, Beds. He matriculated in 1610 and took his B.A. in 1611/12; M.A., in 1615 and his M.D., from King's College, in 1636. His brother, who was also at Cambridge, became a parson and was Rector of a parish in Bedfordshire. The annotation notes are from Venn's Alumni Cantabrigienses, Vol. IV. I have not been able to find out when Dr. Simcotes died. Perhaps I ought to add that I have preserved the original orthography save in the word lettre, which I have extended from the formal contraction of the time.

\title{
ANNOTATION
}

\section{Instruction in the Treatment of Ophthalmia Neonatorum}

At the annual meeting of the British Medical Association held at Eastbourne in July, 1931, a resolution was carried drawing the attention of the General Medical Council to the present unsatisfactory state of the curriculum with regard to the teaching of the treatment of ophthalmia neonatorum to medical students.

It seems a pity that the facilities which exist at St. Margaret's Hospital should not be utilized for medical students in the same manner as they are for pupil midwives; but it is a well-known fact 
that very few medical students have availed themselves of the opportunity in the past; and until a short course is made compulsory there does not appear to be much hope of improvement in this matter.

It seems to us that it would be perfectly practicable to insist on each medical student attending a course of five or six demonstrations before being signed up. Such a course could be held thrice yearly. It would not increase unduly the burden of the present curriculum.

The following communication (May 27, 1932) from the Registrar of the General Medical Council has been received :-

"With reference to your letter of April 22 with regard to ophthalmia neonatorum, I have to say that this was considered by the Education Committee of the Council at their meeting on May 24, when it was resolved :-

That the British Medical Association be informed that it was intended that the care and treatment of ophthalmia neonatorum should be included under 'Diseases of the Eye' in the resolutions of the Council in regard to Professional Education, and it was not considered expedient to refer to specific diseases by name or to define how and where opportunities for studying them should be obtained."

It will be remembered by the older members of the ophthalmic fraternity that a deputation consisting of $\mathrm{Mr}$. Jonathan Hutchinson, Sir William Bowman, Mr. Tweedy, Dr. McKeown, Dr. Brailey and Dr. Abercrombie waited upon the Local Government Board on May 15, 1885, with the object of impressing upon the authorities the importance of ophthalmia neonatorum as the chief cause of preventable blindness in children. . At that time the suggestions of the deputation were held to be impossible of fulfilment, on account of the additional work which would be thrown thereby upon the Registrars of births, whose duties were laid down by Act of Parliament, and whose remuneration was also settled by Act of Parliament. Extra work without extra pay was anathema to the official mind 47 years ago.

Now that ophthalmia neonatorum is a notifiable disease, the objections raised by the then Local Government Board no longer obtain, and the necessity for every medical man to have an adequate knowledge of ophthalmia neonatorum is so obvious that we hope the last word has not been said on this matter. 